
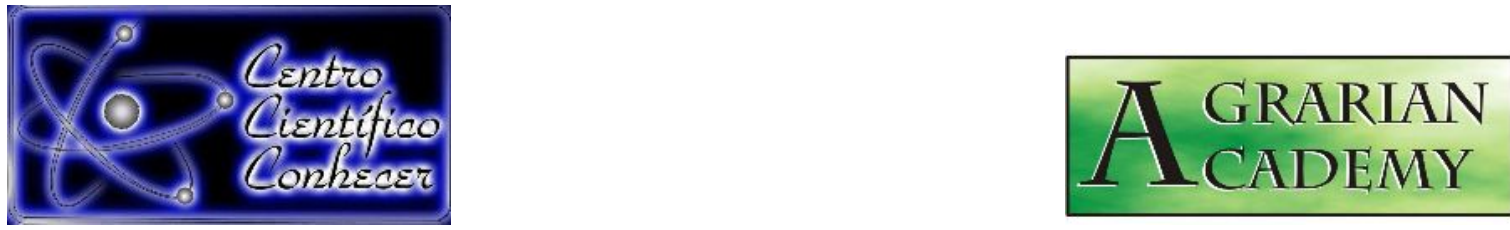

\title{
A IMPLANTAÇÃO DA CAPRINOCULTURA LEITEIRA NO ASSENTAMENTO NOVA ASSUNÇÃO, ARACOIABA-CE
}

Ávila Kedna Alves Maia ${ }^{1}$, Maria Gorete Flores Salles ${ }^{2}$, Ciro de Miranda Pinto ${ }^{3}$, Inti Campos Salles Rodrigues ${ }^{4}$, Aderson Martins Viana Neto ${ }^{5}$

${ }^{1}$ Bacharel em Agronomia da Universidade da Integração Internacional da Lusofonia Afro-Brasileira (UNILAB), Redenção-CE, Brasil.

${ }^{2}$ Professora Doutora do curso de Agronomia da UNILAB, Redenção-CE, Brasil.

E-mail: gorete@unilab.edu.br

${ }^{3}$ Professor Doutor do curso de Agronomia da UNILAB, Redenção-CE, Brasil.

${ }^{4}$ Mestre em Ciências Veterinárias/ Universidade Estadual do Ceará (UECE),

Fortaleza-CE, Brasil.

${ }^{5}$ Professor Doutor Substituto/ Universidade Federal do Ceará (UFC), Fortaleza-CE, Brasil.

Recebido em: 02/06/2019 - Aprovado em: 15/06/2019 - Publicado em: 22/07/2019 DOI: 10.18677/Agrarian_Academy_2019a1

\section{RESUMO}

O projeto caprinocultura leiteira visa melhorar a qualidade de vida de assentamentos e diminuir o êxodo rural dos jovens rurais. Assim, este trabalho objetivou acompanhar a implantação deste projeto no Assentamento Nova Assunção em Aracoiaba-CE, junto às quatro famílias beneficiadas. Cada família recebeu 15 fêmeas e um reprodutor, 3000 raquetes de palma forrageira e $12,5 \mathrm{~kg}$ de sorgo. Todos os animais foram identificados, vermifugados e aplicado ferro e vitamina ADE. $\mathrm{Na}$ palma forrageira foram encontradas contaminações por Diaspis echinocacti e Fusarium oxysporum. A infertilidade das sementes de sorgo fez com que nenhuma germinasse. Das fêmeas recebidas a família 3 manteve $100 \%$ dos animais (15), na família 1 houve duas mortes (86,7\%), família 4 três mortes $(80 \%)$ e na família 2 cinco mortes $(66,7 \%)$. As fêmeas SPRD tinham em média a idade de 19,76 meses e o peso vivo de $26,18 \mathrm{Kg}$, com pelagens predominantemente vermelha (61\%), branca $(20,3 \%)$ e preta (19\%). Os reprodutores eram das raças Saanen (1) e Anglonubiana (3). Houve mortalidade de animais que chegaram ao assentamento pelo estresse durante o transporte, elevado grau de verminose, desidratação e desnutrição. Alguns animais apresentaram linfadenite caseosa, ectima contagioso, ceratoconjuntivite, pediculose e toxemia da gestação. Conclui-se que os projetos produtivos em áreas de assentamento podem vir a ser elementos relevantes para a viabilidade econômica e social das famílias camponesas. No entanto, é preciso mais critérios quanto aos animais selecionados para compor estes projetos, bem como, é imprescindível o acompanhamento com assistência técnica e cursos de capacitação tecnológica.

PALAVRAS-CHAVE: cabra leiteira, produção animal, reforma agrária. 


\title{
THE IMPLEMENTATION OF DAIRY GOAT PRODUCTION IN THE SETTLEMENT NOVA ASSUNÇÃO, ARACOIABA-CE
}

\begin{abstract}
The dairy goat project aims to improve the quality of life of settlements and reduce the rural exodus of rural youth. Thus, this work aimed to accompany the implementation of this project in the Settlement New Assumption in Aracoiaba-CE, together with the four beneficiary families. Each family received 15 goats (nondefined racial pattern) and a buck (Saanen or Anglonubian), 3,000 Opuntia ficus rackets and $12.5 \mathrm{~kg}$ of Sorghum bicolor. All animals were identified, dewormed and applied iron and ADE vitamin. It was identified contaminations by Diaspis echinocacti and Fusarium oxysporum in Opuntia ficus. Moreover, anyone sorghum seeds germinated. These goats received "family 3 " kept $100 \%$ of the animals (15), "family 1 " had your herd reduced due two deaths (86.7\%), family 4 due three deaths $(80 \%)$ and "family 2 " due five deaths (66.7\%). The females had 19.76 months and $26.18 \mathrm{~kg}$ body weight, with predominantly red $(61 \%)$, white $(20.3 \%)$ and black $(19 \%)$ coats. There was mortality of animals that arrived at the settlement due to stress during transportation, high degree of worm infection, dehydration and poor nutrition. Some goats presented caseous lymphadenitis, contagious ecthyma, keratoconjunctivitis, pediculosis and toxemia of gestation. It is concluded that productive projects in settlement areas can become important elements for the economic and social viability of peasant families. However, more criteria are needed for the animals selected to compose these projects, so that is essential to follow up with technical assistance and technological training.
\end{abstract}

KEYWORDS: dairy goat, animal production, land reform.

\section{INTRODUÇÃO}

A pecuária tem sido historicamente a vocação de exploração dos ecossistemas da Caatinga (ARAÚJO FILHO, 2013) sendo a cabra um dos animais de produção, capazes de sobreviver e produzir em condições adversas, pois é um animal rústico, versátil e de fácil manejo, com algumas raças bem adaptadas a região semiárida (SILVA et al., 2015). Neste contexto, a caprinocultura tem importante papel econômico e social para os sertanejos do nordeste brasileiro, por suprir as populações de baixa renda com proteína de elevado valor biológico (VIEIRA et al., 2016), bem como, pela fixação do homem ao campo e a perpetuação da atividade produtiva para as gerações seguintes (BATISTA; SOUZA, 2015).

Com 7,6 milhões de caprinos, a região Nordeste é responsável por mais de $90 \%$ do rebanho nacional, segundo dados do censo agropecuário, salientando que, no Brasil o rebanho caprino cresceu $16 \%$ nos últimos dez anos, totalizando 8,2 milhões de cabeças; na região Nordeste, onde passou de 6,4 milhões para 7,6 milhões, correspondendo a $18,3 \%$ de crescimento; no Norte $(139,7$ mil para 188,6 mil, ou $35 \%$ ) e no Centro-Oeste (75,9 mil para 108,8 mil, ou 43,3\%). Apenas as regiões Sul e Sudeste reduziram o número de caprinos (IBGE, 2017).

O censo agropecuário revela ainda que o número de estabelecimentos agropecuários voltados à caprinocultura teve um crescimento de 16,5\%. Além disso, o total de animais comercializados teve expansão de 65\% (IBGE, 2017). Assim, o sistema de criação de caprinos vem crescendo e se consolidando no mercado, não só nordestino, mas também em outras regiões, pois é uma atividade rentável que aumenta gradativamente, com a vantagem de não requerer investimentos elevados 
e/ou grandes áreas para seu desenvolvimento (LIMA et al., 2015).

Especificamente no semiárido cearense, a caprinocultura leiteira é uma atividade cultural e uma opção viável e rentável para pequenos produtores rurais assentados pela reforma agrária que formam a agricultura familiar. Neste contexto, a Secretária de Desenvolvimento Agrário (SDA) do estado do Ceará em convênio com o Instituto Nacional de Colonização e Reforma Agrária (INCRA) implantou vários projetos produtivos em assentamentos, sendo um destes o da caprinocultura leiteira, como forma de obtenção de alimento nutritivo e saudável pelo leite de cabra, bem como, aumentar a renda das famílias com a comercialização de seus produtos, induzir a capacitação dos assentados na pecuária, pela adoção de tecnologias sustentáveis e eficientes. Contribuindo assim, para a melhoria da qualidade de vida da comunidade do assentamento como um todo, diminuir o êxodo rural por parte dos jovens rurais, além de servir como modelo para as demais comunidades assentadas em regiões de clima semiárido (SDA, 2018).

Portanto, este trabalho objetivou acompanhar todo o processo de implantação do projeto da caprinocultura leiteira no assentamento Nova Assunção em Aracoiaba$C E$, junto às famílias beneficiadas.

\section{MATERIAL E MÉTODOS \\ Localização e caracterização da área de estudo}

O trabalho foi desenvolvido no assentamento federal Nova Assunção cujo código no IBGE é 2301208, o qual possui 17 famílias assentadas numa área de 737,43 ha que abrange duas localidades (Pedra Aguda e Assunção) no município de Aracoiaba, estado do Ceará, situadas às coordenadas geográficas de latitude $4^{\circ} 41^{\prime} 90^{\prime \prime}$ Sul, longitude 38 $76^{\prime} 92^{\prime \prime}$ Oeste e altitude de 88 m na Pedra Aguda e na latitude $4^{\circ} 25^{\prime}$ Sul, longitude $38^{\circ} 46^{\prime \prime}$ Oeste e altitude de $73 \mathrm{~m}$ na Assunção.

O clima da região é tropical quente semiárido, com pluviosidade média anual de 1010,3 $\mathrm{mm}$ no período chuvoso de fevereiro a abril, a temperatura média anual situa-se entre $24-26{ }^{\circ} \mathrm{C}$. O relevo é do tipo maciços residuais, solos podzólico vermelho-amarelo, aluviais e litólicos em vegetação de caatinga arbustiva densa (IPECE, 2017).

\section{Período de estudo}

O estudo foi desenvolvido nos anos de 2017 e 2018, com visitas uma vez por semana, as famílias dos assentados beneficiadas com o projeto da caprinocultura.

\section{Descrição do projeto caprinocultura}

Segundo a SDA (2018) do estado do Ceará, o projeto objetivou estimular a produção agroecológica e estruturar cadeias produtivas de interesse econômico e social, como forma de contribuir para o resgate da dignidade humana e social de famílias assentadas no semiárido com o perfil do programa Bolsa Família.

No assentamento Nova Assunção, o projeto contemplou 4 famílias. Cada família recebeu 15 fêmeas SPRD (Sem Padrão Racial Definido) e um reprodutor exótico, cujas raças eram: Saanen (1) e Anglonubiana (3), que foram distribuídos aleatoriamente. $O$ projeto constava ainda de três mil raquetes de palma forrageira (Opuntia cochenillifera) e $10 \mathrm{Kg}$ de sementes do sorgo forrageiro (Sorghum bicolor), por família contemplada, com o objetivo de preparar o suporte nutricional para os animais. Posteriormente, foram entregues os kits de higienização da ordenha.

O projeto caprinocultura leiteira foi acompanhado a partir da entrega dos animais em julho de 2017 (Figura 1) e, a parir desta data foram coletados os dados junto aos assentados contemplados. 


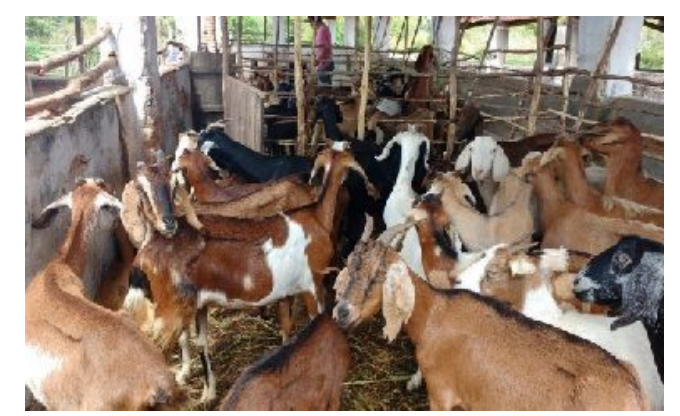

FIGURA 1. Caprinos recebidos

Fonte: Os autores

\section{Caracterização do trabalho e coleta dos dados}

Todos os animais recebidos pelas famílias beneficiadas no projeto foram identificados por brincos de plástico numerados (Figura 2), neste momento foram verificadas as seguintes variáveis: sexo e cor do pelame e estimadas a idade e o peso.

Após a realização das fichas zootécnicas, todos os animais não prenhes foram vermifugados por via oral e aqueles, aparentemente mais debilitados receberam por via intramuscular uma dose de ferro e vitamina ADE (Figura 3). A partir de então, foram coletados os dados reprodutivos como, data de parição, tipo de parto, sexo e peso das crias nascidas, bem como a data de estro e a identificação do reprodutor que fez a monta natural.

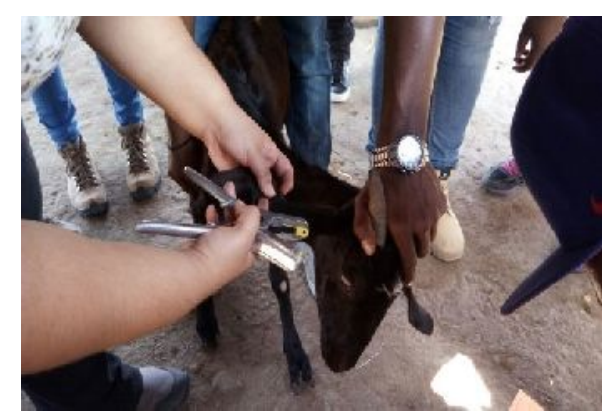

FIGURA 2. Identificação dos animais Fonte: Os autores

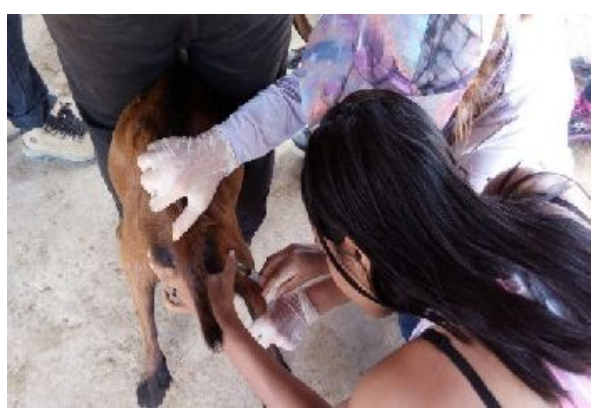

FIGURA 3. Aplicação de ferro e ADE Fonte: Os autores

Também foram anotados os dados sanitários dos quatro rebanhos, acompanhando o surgimento de doenças infectocontagiosas após a chegada dos animais no assentamento, que passaram por várias situações de estresse durante o transporte, desde a compra no local de origem (Bahia).

Para uma melhor profilaxia sanitária e o bem-estar dos animais, em cada família foram observadas nas instalações preparadas para receber os animais, a questão da ambiência em pleno semiárido e a implantação de bancos de proteínas com leguminosas adaptadas ao clima quente, para a suplementação alimentar.

\section{Análise estatística}

Os dados coletados foram organizados e analisados por meio de métodos da estatística descritiva, com sínteses apresentadas na forma de tabelas pelo Excel. 


\section{RESULTADOS E DISCUSSÃO \\ Animais - dados numéricos e identificação zootécnica}

O projeto caprinocultura leiteira entregou no assentamento Nova Assunção 60 fêmeas e 4 reprodutores, distribuídos equitativamente entre 4 famílias, sendo 15 fêmeas e um reprodutor para cada família beneficiada.

Após cinco meses do recebimento dos animais foi feita uma visita a cada família para a realização da conferência numérica nos rebanhos, sendo encontrado na família 1 um total de 20 animais, onde das 15 fêmeas recebidas, duas morreram e três pariram de parto duplo, com o nascimento de 6 crias (5 fêmeas e 1 macho), o reprodutor continuava no plantel. $\mathrm{Na}$ família 2 foram encontrados 12 animais, onde morreram 5 fêmeas do projeto e uma pariu de parto simples uma cabrita, com o reprodutor presente rebanho. Na família 3 foram observados 18 animais e estavam presentes todas as fêmeas recebidas e o reprodutor, com a parição de duas cabras de parto simples, sendo um macho e uma fêmea. Na família 4 estavam 15 animais e houve a morte de três das fêmeas recebidas no projeto, mas duas cabras pariram duas cabritas nascidas de parto simples, estando o bode no plantel (Tabela 1).

TABELA 1 - Fêmeas (adultas e cabritas), machos (adultos e cabritos) e a cor do pelame (branco, vermelho e preto) de animais dos assentados.

\begin{tabular}{llllcccc}
\hline & \multicolumn{2}{l}{ FÊMEAS } & \multicolumn{2}{c}{ MACHOS } & \multicolumn{3}{c}{ PELAME } \\
\hline Assentados & Adultas & Cabritas & Adulto & Cabritos & Branco & Vermelho Preto \\
\hline Família 1 & 13 & 5 & 1 & 1 & 6 & 8 & 6 \\
Família 2 & 10 & 1 & 1 & 0 & 2 & 8 & 2 \\
Família 3 & 15 & 1 & 1 & 1 & 3 & 14 & 1 \\
Família 4 & 12 & 2 & 1 & 0 & 3 & 9 & 3 \\
\hline
\end{tabular}

Assim, percebe-se que ocorreram mortes e nascimentos nos rebanhos, bem como, a família 3 manteve $100 \%$ das fêmeas recebidas no projeto (15), seguida da família 1 que teve duas mortes (86,7\%), na família 4 com três óbitos (80\%) e família $2(66,7 \%)$ onde houve o maior número de perdas, com o óbito de cinco fêmeas.

A morte dos animais, provavelmente esteja relacionada a alguns fatores estressantes como: o transporte do local de onde foram adquiridos os animais, no sertão da Bahia até o local de entrega, no semiárido do maciço de Baturité no Ceará, bem como a desnutrição e às verminoses. Esses fatores aliados à ausência de assistência técnica e às más condições de sanidade dos animais entregues nesse tipo de projeto levam na maioria das vezes ao insucesso, à insatisfação dos contemplados e à falta de motivação para a implantação de novos projetos.

\section{Animais - tipos raciais e cor de pelame}

Foi verificado que nos animais recebidos, todas as fêmeas eram sem padrão racial definido (SPRD) constando de várias colorações das pelagens, o que caracteriza este tipo de grupamento genético. No entanto, entre os animais recebidos e nascidos predominava a pelagem vermelha $(61 \%)$, seguidos da branca $(20,2 \%)$ e a preta (19\%), caracterizando assim a maior parte dos caprinos criados no nordeste brasileiro. Riet-Correa et al. (2013) trabalhando no sertão paraibano em cinco propriedades de criação de cabras, também não encontrou em nenhuma das propriedades um rebanho com padrão racial definido. 


\section{Animais - idade e peso}

A idade média dos animais recebidos pelo projeto caprinocultura leiteira (Tabela 2) foi de 19,76 meses com peso vivo médio de 26, $18 \mathrm{Kg}$. Observa-se que na família 4 os animais tinham a menor média de idade (17,53 meses) com o maior peso médio $(28,68 \mathrm{Kg})$.

TABELA 2- Média e erro padrão da idade e peso de animais do projeto caprino de leite do assentamento Nova Assunção, Aracoiaba-CE.

\begin{tabular}{lllll}
\hline & \multicolumn{2}{c}{ Idade (meses) } & \multicolumn{2}{c}{ Peso $(\mathrm{kg})$} \\
\hline Assentados & Media $\pm \mathrm{EP}$ & $\mathrm{CV}(\%)$ & Media \pm EP & CV (\%) \\
\hline Família 1 & $22,71 \pm 4,48$ & 73,96 & $25,14 \pm 3,68$ & 54,84 \\
Família 2 & $20,72 \pm 3,65$ & 74,70 & $22,83 \pm 2,45$ & 45,54 \\
Família 3 & $18,08 \pm 2,90$ & 55,57 & $28,08 \pm 4,08$ & 50,34 \\
Família 4 & $17,53 \pm 3,30$ & 72,95 & $28,68 \pm 2,92$ & 39,5 \\
\hline
\end{tabular}

\section{Alimento - palma forrageira e sorgo}

No projeto houve a doação de 12 mil raquetes de palma forrageira, para que, cada família cultivasse 3 mil raquetes em área próxima à instalação dos apriscos.

$\mathrm{Na}$ palma forrageira (Opuntia cochenillifera) cultivada pelas 4 famílias do projeto foram encontradas contaminações por Diaspis echinocacti (Figura 4) que causa danos e prejuízos sendo popularmente conhecida como cochonilha de escamas (NHAGA et al., 2018) e pelo fungo Fusarium oxysporum (Figura 5) conhecida como fusariose, com grande perda das plantas na maioria dos plantios realizados pelos assentados em áreas expostas ao sol e outras com sombreamento, mas sem o uso de adubação. Esta doença, a fusariose é um dos maiores problemas enfrentados pelos produtores de palma forrageira (COLEMAN, 2016).

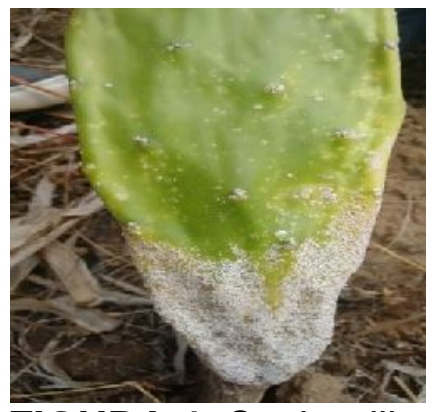

FIGURA 4. Cochonilha Fonte: Os autores

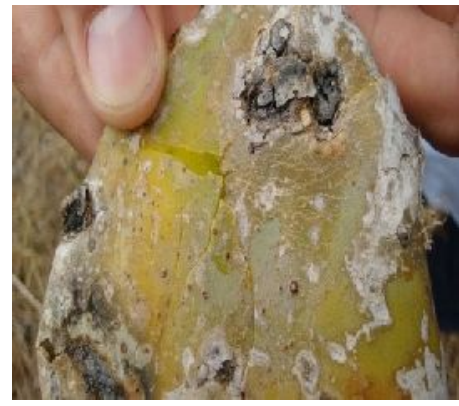

FIGURA 5. Fusariose

Fonte: Os autores

Possivelmente as raquetes recebidas pelos agricultores familiares tenham vindo contaminadas, pois no assentamento não havia o cultivo desta planta e ademais, a cultura é bem adaptada às condições adversas do semiárido por ser nativa de regiões quentes e secas.

A palma forrageira é uma cactácea largamente difundida no nordeste brasileiro por ser adaptada ao clima quente, é ainda, uma alternativa na alimentação de rebanhos no semiárido nordestino de comprovada eficiência na nutrição dos ruminantes (PEIXOTO et al., 2018), por ser uma boa fonte de água, servindo como reserva alimentar estratégica para o período de seca (CARVALHO et al., 2018). Almeida (2012) cita que a palma é uma cultura relativamente exigente quanto às características físico-químicas do solo com fertilidade, bem como, boa drenagem e adubação. 
O projeto também forneceu ao assentamento 50 quilos de sorgo forrageiro (Sorghum bicolor) onde cada família beneficiada semearia 12,5 quilos de sementes da planta, que serviriam para a alimentação dos animais. No entanto, a infertilidade das sementes fez com que nenhuma germinasse, bem como houve dificuldades com relação a falta de água para a implantação dos bancos de alimentos.

\section{Instalações e sistema de criação}

No assentamento Nova Assunção a maioria das instalações onde os animais pernoitam, são rústicas feitas de madeira extraída da mata (sabiá) com o piso de chão batido (75\%), somente uma família possuía curral de alvenaria com piso cimentado (25\%); sendo as coberturas dos telhados com telha de barro $(50 \%)$ e palha de carnaúba (50\%), com cochos e bebedouros de cimento (25\%) e de vasilhames plásticos (75\%). Nas áreas descobertas há poucas árvores para 0 sombreamento. Estes resultados se assemelham aos encontrados por Silva et al. (2015) onde diagnosticaram que $100 \%$ das propriedades nordestinas possuíam apriscos rústicos e de chão batido.

Em todas as famílias do projeto, o sistema de criação é semi-intensivo, isto é, os animais são soltos a pasto nativo durante o dia, com o retorno para o curral no final da tarde. Os animais são soltos no pasto na maior parte do tempo, porém, a sua alimentação é complementada com uma ração suplementar, para que possa fornecer nutrientes aos caprinos que o pasto talvez não possua. Diniz et al. (2014) e Rodrigues et al. (2016) encontraram em 100\% das propriedades no semiárido de Pernambuco a forma extensiva de criação de caprinos leiteiros.

\section{Instalações - água fornecida aos caprinos}

Em três, das quatro famílias $(1,2$ e 3 ) beneficiadas pelo projeto caprinocultura leiteira, a água usada é retirada de cisternas que a casa da família do assentado possui (Figura 6), advindas dos projetos governamentais das tecnologias de convivência com a seca, que viabilizam a captação e o armazenamento da água durante o período das chuvas, para o posterior uso na subsistência da família e criação dos animais ao redor da casa durante a outra metade de período seco do ano. Na família 4, a água utilizada era retirada do açude próximo ao aprisco dos animais.



FIGURA 6. Cisterna

Fonte: Os autores

Após coletada, a água era colocada em bebedouros improvisados com tambores plásticos, suspensos na altura da boca dos animais, que esporadicamente (uma vez por semana) eram limpos para a retirada de sujidades. 


\section{Sanidade - aplicação do Método FAMACHA®}

Todos os caprinos foram analisados pelo método FAMACHA®, que consiste em verificar a mucosa ocular do animal e distinguir o grau de coloração que varia entre vermelho robusto até branco, para avaliar o nível de parasitismo (Figura 7). 0 exame foi sob luz natural e, com o dedo polegar pressionando levemente a pálpebra inferior para baixo, foi observada a coloração na parte medial da conjuntiva, determinando assim o grau de coloração seguindo a tabela ilustrativa (Figura 8).

\begin{tabular}{cccl}
\hline $\begin{array}{c}\text { Grau } \\
\text { Famacha }\end{array}$ & Coloraçăo* & $\begin{array}{c}\text { Variação do hematócrito } \\
(\%)\end{array}$ & $\begin{array}{c}\text { Atitude } \\
\text { clínica** }\end{array}$ \\
\hline 1 & Vermelho robusto & Acima de 28 & Não tratar \\
2 & Vermelho rosado & 23 a 27 & Năo tratar \\
3 & Rosa & 18 a 22 & Tratar! \\
4 & Rosa pálido & 13 a 17 & Tratar !! \\
5 & Branco & Abaixo de 12 & Tratar !!! \\
\hline
\end{tabular}

FIGURA 7. Tabela FAMACHA®

Fonte: Van Wyk et al. (1999)

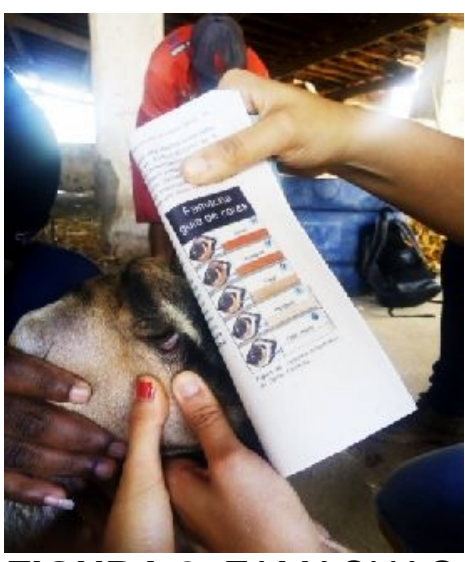

FIGURA 8. FAMACHA®

Fonte: Os autores

Os animais que apresentaram algum grau de parasitismo através da coloração da conjuntiva segundo a tabela do método foram vermifugados por via oral com o princípio ativo albendazole. Quatro semanas após foram feitas novas verificações nos animais tratados onde foi constatada que houve melhorias com a modificação da cor da conjuntiva ocular.

Pelo crescente problema de resistência dos parasitas aos vermífugos (BORGES et al., 2015), métodos com o pressuposto de analisar a sanidade do animal (BALTRUSIS et al., 2018) e constatar o parasitismo ou não boa sensibilidade, para identificar os animais que necessitam receber o tratamento químico são importantes alternativas aos métodos tradicionais (FERNANDES et al., 2015). Uma das possibilidades, é o método FAMACHA® pela observação visual da conjuntiva ocular dos animais, que segue a técnica descrita por Van Wyk et al. (1999), onde comprovaram existir uma correlação entre a coloração da conjuntiva e valor do hematócrito com a incidência de parasitismo do parasita hematófago Haemonchus contortus que é o mais danoso aos caprinos e provoca anemia, emagrecimento, edema submandibular, diarreia podendo levar à morte (SILVA et al., 2017).

No nordeste brasileiro é comum uma alta frequência de verminose em rebanhos caprinos, sendo um dos maiores e mais graves problemas de sanidade nas criações, em decorrência das perdas econômicas pela queda da produção e a morte dos animais (RODRIGUES et al., 2016). Limeira et al. (2018) concluíram do estudo no semiárido paraibano, que as maiores frequências de caprinos positivos nos exames parasitológicos foram observadas nos animais com origem na Bahia, local de onde também vieram os caprinos entregues no projeto caprinocultura leiteira que atendeu as famílias do assentamento Nova Assunção no Ceará.

Ademais, foi orientado aos assentados que a retirada das fezes dos currais e a limpeza do local na área de pastejo é fator importante no controle do parasitismo, bem como a limpeza dos comedouros e depósitos onde a água é ofertada.

AGRARIAN ACADEMY, Centro Científico Conhecer - Goiânia, v.6, n.11; p. 82019 


\section{Sanidade -doenças que ocorreram nos animais}

Em todas as famílias contempladas no projeto houve casos de verminoses e algum tipo de enfermidade nos caprinos, especialmente advindas de deficiências no manejo sanitário, como linfadenite caseosa, ectima contagioso, ceratoconjuntivite, pediculose, toxemia da gestação e abortos (Tabela 3).

TABELA 3- Doenças que acometeram os animais recebidos pelas famílias do projeto no Assentamento Nova Assunção, Aracoiaba-CE.

\begin{tabular}{ccccccc}
\hline \multicolumn{7}{c}{ DOENÇAS } \\
\hline ASSENTADOS & $\begin{array}{c}\text { Linfadenite } \\
\text { caseosa }\end{array}$ & $\begin{array}{c}\text { Ectima } \\
\text { contagioso }\end{array}$ & $\begin{array}{c}\text { Cerato } \\
\text { conjutivite }\end{array}$ & Pediculose & $\begin{array}{c}\text { Toxemia } \\
\text { da } \\
\text { gestação }\end{array}$ & Aborto \\
\hline Família 1 & $\mathrm{X}$ & $\mathrm{X}$ & $\mathrm{X}$ & $\mathrm{X}$ & & $\mathrm{X}$ \\
Família 2 & $\mathrm{X}$ & & & & $\mathrm{X}$ & $\mathrm{X}$ \\
Família 3 & $\mathrm{X}$ & & $\mathrm{X}$ & & $\mathrm{X}$ \\
Família 4 & & &
\end{tabular}

Em rebanhos no Maranhão, Teixeira et al. (2015) encontraram casos de verminoses, linfadenite caseosa, aborto, ectima contagioso, ceratoconjuntivite, pneumonia e diarreia.

Neste estudo, a linfadenite caseosa ocorreu em 50\% das famílias do projeto, esta doença infectocontagiosa de caráter crônico é causada pelo agente bacteriano Corynebacterium pseudotuberculosis, sendo popularmente conhecida como mal do caroço pela característica de aparecer granulomas (caroços) cutâneos e viscerais (SÁ et al., 2018).

O ectima contagioso ocorreu somente na família 2, correspondendo a $25 \%$ de ocorrência no assentamento. A doença é viral causada por um Parapoxvirus e, conhecida como estomatite pustular contagiosa ou boqueira, que se caracteriza pelo desenvolvimento de lesões pustulares e crostosas, especialmente, na pele do focinho e lábios (PANZIERA et al., 2016). O aparecimento da doença se dá por animais vindos de outras propriedades, devido à imunossupressão causada pelo estresse do transporte e mudança de ambiente (SARDI et al., 2012). A doença é potencialmente zoonótica, podendo afetar pessoas que trabalham diretamente com esses animais. Inicialmente, aparecem pequenos pontos avermelhados nos lábios. Posteriormente, há formação de pústulas que se rompem e se transformam em crostas secas, que permanecem infectantes por meses ou até anos no ambiente. A contaminação ocorre por ferimentos em locais contaminados e, as pastagens abrasivas são importantes fontes de infecção, introduzindo o vírus na mucosa oral de onde se espalha para os lábios, gengiva, narinas, úbere e outras partes do corpo (EBLING et al., 2015).

A ceratoconjuntivite que teve $50 \%$ de ocorrência (famílias 1 e 4 ) no assentamento é uma doença infecciosa, também conhecida como doença do olho rosado, pela inflamação da córnea e conjuntiva, que ocorre mais na época chuvosa (CARDOSO et al., 2015). O caráter infeccioso dos surtos é causado por bactérias que podem ser transmitidas por contato direto entre animais enfermos e sadios (CHAVES et al., 2008), por moscas ou outros insetos, fômites e pelas mãos dos tratadores. Também são fatores predisponentes, poeira, gravetos, forragem seca e o vento, que podem lesar superficialmente os olhos dos animais e iniciar o processo infeccioso (SANTANA et al., 2011).

$\mathrm{Na}$ família 2 foi detectada a presença de piolhos nos animais (pediculose) com 
a infestação abrangendo todos os animais deste assentado, no entanto a ocorrência no assentamento foi de $25 \%$. Em dois assentamentos no Maranhão Silva et al. (2015) encontraram em rebanhos caprinos uma grande infestação por piolhos sugadores, que são um dos principais causadores de problemas e, quando não diagnosticados, podem levar os animais à morte ou diminuição acentuada da produção de leite e carne, além da perda de peso. Os piolhos acometem os caprinos durante todos os meses do ano, porém com maior intensidade no período seco.

A toxemia da gestação ou da prenhez ocorreu em duas fêmeas na família 4, correspondendo a $25 \%$ de ocorrência no assentamento. É uma doença metabólica que ocorre entre as duas a quatro últimas semanas de gestação, associada à hipercetonemia e hipoglicemia, comum em animais subnutridos e estressados caracterizada por anorexia, disfunção neurológica progressiva, decúbito e morte (SOUTO et al., 2017),

Os casos de aborto que ocorreram nas famílias 1 e 4 (50\%) foram mais frequentes logo após a chegada dos animais no assentamento, em consequência do estresse durante o transporte, sendo mais frequentes nas fêmeas mais desnutridas com sinais de verminose como magreza e pelos ásperos e sem brilho. Em caprinos na Paraíba, Santos et al. (2011) encontraram aborto (65\%), mamite $(60 \%)$, linfadenite caseosa $(51,7 \%)$ e ceratoconjuntivite $(50 \%)$ como as enfermidades de maior relevância, destacando-se as duas primeiras por estarem relacionadas diretamente com a produção de leite. Em Sergipe, Santos et al. (2014) relataram em pesquisa realizada junto aos produtores de leite caprino a ocorrência de linfadenite caseosa $(57,14 \%)$, edema submandibular $(14,3 \%)$, diarreia $(57,1 \%)$, anemia $(42,8)$, aborto (19\%), ceratoconjuntivite $(47,6 \%)$ e ectima contagioso $(14,3 \%)$. Santos et al. (2018) citam que as três principais enfermidades identificadas no interior do Pernambuco foram a linfadenite caseosa, a verminose e a ceratoconjuntivite, enquanto que Rodrigues et al. (2016) verificaram que as principais enfermidades que acometem os caprinos leiteiros são a diarreia e edema submandibular por verminose, linfadenite caseosa com abscessos subcutâneos, piolho e mastite.

\section{CONCLUSÕES}

Os projetos produtivos em áreas de assentamento são relevantes para a viabilidade econômica e social das famílias camponesas. No entanto, critérios mais exigentes e específicos quanto aos animais selecionados para compor estes projetos, bem como, o acompanhamento com assistência técnica pelos órgãos implantadores dos projetos produtivos, são imprescindíveis.

Também são sugeridas parcerias das universidades com as instituições que fazem extensão rural, no intuito de que realizem a capacitação técnica e a assistência agropecuária aos assentados. Tendo em vista, orientar os produtores rurais quantos aos manejos, sanitário, reprodutivo e nutricional dos rebanhos caprinos, bem como, o conhecimento das técnicas de conservação de forragem para as épocas secas do ano.

\section{REFERÊNCIAS}

ALMEIDA, R.F. Palma forrageira na alimentação de ovinos e caprinos no semiárido brasileiro. Revista Verde de Agroecologia e Desenvolvimento Sustentável, v. 7, n. $4, \quad$ p. $\quad 08-14, \quad 2012 . \quad$ Disponível em: https://www.gvaa.com.br/revista/index.php/RVADS/article/view/1113/1334 Acesso em: $22 / 05 / 2019$ 
ARAÚJO FILHO, J.A. Manejo pastoril sustentável da caatinga. Recife-PE: Projeto Dom Helder Câmara. 2013. 204p. ISBN: 978-85-64154-04-9. Disponível em: http://repositorio.iica.int/bitstream/11324/4209/1/BVE17099221p.pdf Acesso em: $21 / 05 / 2019$

BALTRUŠIS, P.; HALVARSSON, P.; HÖGLUND, J. Exploring benzimidazole resistance in Haemonchus contortus by next generation sequencing and droplet digital PCR. International Journal for Parasitology: Drugs and Drug Resistance, v. $\quad 8, \quad$ n. $3, \quad$ p. 411-419, 2018. Disponível em: https://www.sciencedirect.com/science/article/pii/S2211320718300848?via\%3Dihub DOI: $10.1016 / j . j$.jpddr.2018.09.003.

BATISTA, N.L.; SOUZA, B.B. Caprinovinocultura no semiárido brasileiro - fatores limitantes e ações de mitigação. Agropecuária Científica no Semiárido, v. 11, n. 2, p. 01-09, 2015.2 Disponível em: http://revistas.ufcg.edu.br/acsa/index.php/ACSA/article/download/522/pdf Acesso em: 22/05/2019.

BORGES S.L.; OLIVEIRA, A.A.; MENDONÇA, R.L.; LAMBERT, S.M.; VIANA, J.M. et al. Resistência anti-helmíntica em rebanhos caprinos nos biomas Caatinga e Mata Atlântica. Pesquisa Veterinária Brasileira, v. 35, n. 7, p. 643-648, 2015. Disponível em: http://www.scielo.br/pdf/pvb/v35n7/1678-5150-pvb-35-07-00643.pdf DOI: 10.1590/S0100-736X2015000700007.

CARDOSO, M.V.; PINO, F.A.; FEDERSONI, I.S.P.; LUCCHESE FILHO, A.; FELÍCIO, A.L. Caracterização da caprinocultura e ovinocultura no estado de São Paulo. Arquivos do Instituto Biológico, v. 82, p. 1-15, 2015. Disponível em: http://www.scielo.br/pdf/aib/v82/1808-1657-aib-000592013.pdf DOI: 10.1590/18081657000592013

CARVALHO, C.B.M.; EDVAN, R.L.; CARVALHO, ML.A.M.; REIS, A.L.A., NASCIMENTO, R.R. Uso de cactáceas na alimentação animal e seu armazenamento após colheita. Archivos de Zootecnia, v. 67, n. 259, p. 440-446, 2018. Disponível em: https://www.uco.es/ucopress/az/index.php/az/article/download/3803/2282 Acesso em: $23 / 05 / 2019$

CHAVES, N.S.T.; LIMA, A.M.V.; AMARAL, A.V.C Surto de ceratoconjuntivite infecciosa em ovinos causada por Moraxella spp. no estado de Goiás, Brasil. Ciência Animal Brasileira, v. 9, n. 1, p. 256-261, 2008. Disponível em: https://revistas.ufg.br/vet/article/view/3695 Acesso em: 26/05/2019

COLEMAN, J.J. The Fusarium solani species complex: ubiquitous pathogens of agricultural importance. Molecular Plant Pathology, v. 17, n. 2, p. 146-158, 2016. Disponível em: https://onlinelibrary.wiley.com/doi/full/10.1111/mpp.12289 DOI: 10.1111/mpp.12289

DINIZ, W.J.S.; ALMEIDA, R.B.; CARDOZO, R.F.; PEDROSA, C.M.; FEITOSA, P.J.S. et al. Características gerais de produção de caprinos leiteiros em Paranatama, PE. Acta Veterinaria Brasilica, v. 8, n. 2, p. 113-120, 2014. Disponível em: https://periodicos.ufersa.edu.br/index.php/acta/article/view/3429

DOI: 
10.21708/avb.2014.8.2.3429

EBLING, R.C.; LIMANA, J.F.T.; MARCHIORETTO, G.P.; STEFANELLO, S.; LEAL, M.L.R. Ectima contagioso em ovinos da região centro-oeste do Rio Grande do Sul. Enciclopédia Biosfera, Centro Científico Conhecer, v. 11 n. 22; p. 1042-1048, 2015. Disponível em: http://www.conhecer.org.br/enciclop/2015c/agrarias/Ectima\%20contagioso.pdf DOI: 10.18677/Enciclopedia_Biosfera_2015_140

FERNANDES, M.A.M.; GILAVERTE, S.; BUZATTI, A.; SPRENGER, L.K.; SILVA, C.J.A. et al. Método FAMACHA para detectar anemia clínica causada por Haemonchus contortus em cordeiros lactentes e ovelhas em lactação. Pesquisa Veterinária Brasileira, v. 35, n. 6, p. 525-530, 2015. Disponível em: http://www.scielo.br/pdf/pvb/v35n6/1678-5150-pvb-35-06-00525.pdf DOI: 0.1590/S0100-736X2015000600006

IBGE - Instituto Brasileiro de Geografia e Estatística. Censo Agropecuário. 2017. Disponível em: http://www.brasil.gov.br/noticias/economia-e-financas/2018/08/censoagropecuario-rebanho-caprino-aumentou-16-no-brasil Acesso em: 12/05/2019.

IPECE - Instituto de Pesquisa e Estratégia Econômica do Ceará. Perfil Municipal de Aracoiaba. $2017 . \quad$ Disponível em http://www.ipece.ce.gov.br/perfil_basico_municipal/2017/Aracoiaba.pdf. Acesso em: 12/05/2019.

LIMA, F.T.; STURN, R.M.; TAVOLARO, P.; RIBEIRO, A.R.B.; SOUSA, V.A.F. Estudo exploratório do mercado das potencialidades de consumo do leite de cabra e seus derivados entre paulistanos. Informações Econômicas, v. 45, n. 3, p. 30-38, 2015. Disponível em: http://www.iea.sp.gov.br/ftpiea/publicacoes/ie/2015/tec03-0615.pdf Acesso em: 15/05/2019

LIMEIRA, C.H.; ATHAYDE, A.C.R.; ALVES, J.R.A.; LIMA, G.M.S.; LIMEIRA, M.Q.R. et al. Parasitoses gastrintestinais de caprinos e ovinos comercializados na feira de animais de Tabira, Sertão de Pernambuco. Revista Agropecuária Técnica, v. 39, n. 1, p. 87-95, 2018. http://www.periodicos.ufpb.br/index.php/at/article/view/32872 Acesso em: 15/05/2019

NHAGA, A.O.; PINTO, C.M.; SALLES, M.G.F.; PINTO, O.R.O.; SOUSA, F.A. Controle da cochonilha de escama da palma forrageira com o uso de extrato de nim. Enciclopédia Biosfera, Centro Científico Conhecer, v. 15 n. 28; p. 332-340, 2018. Disponível

em:

http://www.conhecer.org.br/enciclop/2018B/AGRAR/Controle\%20da\%20cochonilha.p df DOI: 10.18677/EnciBio_2018B28

PANZIERA, W.; LORENZETT, M.P.; HAMMERSCHMITT, M.E.; SLAVIERO, M.; CARDOSO, H.M. Surto de ectima contagioso em ovinos no Rio Grande do Sul, Brasil. Acta Scientiae Veterinariae, v. 44, n. 179, p. 1-4, 2016. Disponível em: http://www.ufrgs.br/actavet/44-suple-1/CR_179.pdf Acesso em: 20/05/2019

PEIXOTO, M.J.A.; CARNEIRO, M.D.S.; AMORIM, D.S.; EDVAN, R.L.; PEREIRA, E.S. et al. Características agronômicas e composição química da palma forrageira em função de diferentes sistemas de plantio. Archivos de Zootecnia, v. 67, n. 257, 
p. 35-39, 2018. Disponível em: https://www.uco.es/ucopress/az/index.php/az/article/download/3489/2120 Acesso em: $23 / 05 / 2019$

RIET-CORREA, B.; SIMÕES, S.V.D.; PEREIRA FILHO, J.M.; AZEVEDO, S.S.; MELO, D.B. et al. Sistemas produtivos de caprinocultura leiteira no semiárido paraibano: caracterização, principais limitantes e avaliação de estratégias de intervenção. Pesquisa Veterinária Brasileira, v. 33, n. 3, p. 345-352, 2013. Disponível em: http://www.scielo.br/pdf/pvb/v33n3/12.pdf Acesso em: 12/05/2019.

RODRIGUES, B.R.; COELHO, M.C.S.C.; COELHO, M.I.S. Aspectos sanitários e de manejo em criações de caprinos leiteiros produzidos na comunidade de Caroá, distrito de Rajada, Petrolina-PE. Revista Brasileira de Agropecuária Sustentável, v. $6, \quad$ n. 2, p. 9-18, 2016. Disponível em: https://periodicos.ufv.br/ojs/rbas/article/view/2902 DOI: 10.21206/rbas.v6i2.324

SÁ, M.C.A.; ROCHA FILHO, J.T.R.; ROSA, D.S.; OLIVEIRA, S.A.S.; FREIRE, D.P. et al. Linfadenite caseosa em caprinos e ovinos: Revisão. PUBVET, v. 12, n. 11, a 202, p. 1-13, 2018. Disponível em: http://www.pubvet.com.br/artigo/5252/linfadenitecaseosa-em-caprinos-e-ovinos-revisatildeo DOI: 10.31533/pubvet.v12n11a202.1-13.

SANTANA, A.F.; MAGALHÃES, V.R.; BITTENCOURT, C.N.; SILVA, I.P. Eficiência do nitrato de prata a $4 \%$ e da oxitetraciclina spray no controle da ceratoconjuntivite em caprinos e ovinos no semi-árido baiano. PUBVET, v. 5, n. 29, ed. 176, a. 1189, p. 1-10, 2011. Disponível em: http://www.pubvet.com.br/uploads/15dffa6086b0f14b8434146d8e23f4ae.pdf Acesso em:26/05/2019

SANTOS, T.C.P.; ALFARO, C.E.P.; FIGUEIREDO, S.M. Aspectos sanitários e de manejo em criações de caprinos e ovinos na microrregião de Patos, região semiárida da Paraíba. Ciência Animal Brasileira, v. 12, n. 2, p. 206 - 212, 2011. Disponível em: https://www.revistas.ufg.br/vet/article/view/4420/9214 DOI: 10.5216/cab.v12i2.4420

SANTOS, G.R.; MENDONÇA, R.C.; SILVA, M.A.; QUEIROZ, L.O. Caracterização da caprinocultura na bacia leiteira sergipana. Scientia Plena, v. 10, n. 11, p. 81018111, 2014.2 Disponível em: https://www.scientiaplena.org.br/sp/article/viewFile/1995/1071 Acesso em: 18/05/2019.

SANTOS, R.N.; VICENTE, S.L.A.; FERREIRA, J.A.S.; YAMAMOTO, S.M.; PEIXOTO, R.M. et al. Aspectos epidemiológicos da criação de caprinos leiteiros em comunidades rurais dos municípios de Petrolina e Santa Maria da Boa Vista, PE. II Simpósio de Produção Animal da UFRPE-UAST. ISSN 2448-4644. 3p. 2018. Disponível em: https://ainfo.cnptia.embrapa.br/digital/bitstream/item/178280/1/Daniel2018.pdf Acesso em 26/05/2019

SARDI, S.I; MAIA NETO, A.L.; OLIVEIRA, A.; AGAPITO, R.; SERAFIM, W. et al. Primeiro relato do vírus Orf em rebanhos caprinos do semiárido brasileiro. Revista Instituto Adolfo Lutz, v. 71, n. 3, p. 597-600, 2012. Disponível em: http://ses.sp.bvs.br/lildbi/docsonline/get.php?id=4074 Acesso em: 19/05/2019 
SDA. Secretaria do Desenvolvimento Agrário do estado do Ceará. Caprinocultura: 11.438 animais entregues a 743 agricultores familiares. 2018. Disponível em: https://www.sda.ce.gov.br/2018/12/20/caprinocultura-11-438-animais-entregues-a743-agricultores-familiares/ Acesso em: 22/05/2019

SILVA. I.C.S.; BRITO, D.R.B.; SOARES, E.D.; BRITO, A.V.M.; COELHO, A.P. et al. Caracterização zootécnica e econômica dos criadores de caprinos em área de assentamento rural no estado do Maranhão. Revista Brasileira de Agropecuária

Sustentável, v. $5, \quad$ n. $1, \quad$ p. 1-11, 2015. Disponível em: https://periodicos.ufv.br/ojs/rbas/rt/printerFriendly/2891/0 10.21206/rbas.v5i1.313

SILVA, D.G.; MENEZES, B.M.; BETTENCOURT, A.F.; FRANTZ, A.C.; CORRÊA, M.R. et al. Método FAMACHA® como ferramenta para verificar a infestação parasitária ocasionada por Haemonchus spp. em ovinos. PUBVET, v. 11, n. 10, p. 1015-1021, 2017.2 Disponível em: http://www.pubvet.com.br/artigo/4141/meacutetodo-famachareg-como-ferramentapara-verificar-a-infestaccedilatildeo-parasitaacuteria-ocasionada-por-haemonchusspp-em-ovinos Acesso em: 18/05/2019

SOUTO, R.G.C.; SOARES, G.S.L.; MACEDO, A.T.M.; CAJUEIRO, J.F.P.; GONÇALVES, D.N.A. et al. Valores de $\beta$-hidroxibutirato, ácidos graxos não esterificados, cortisol e insulina de cabras leiteiras com toxemia da prenhez subclínica durante o período de transição. Revista Acadêmica: Ciência Animal, v. 15, supl. 2, p. 253-254, 2017. Disponível em: https://periodicos.pucpr.br/index.php/cienciaanimal/article/view/17277/16560～DOI: 10.7213/academica.15.S02.2017.126

TEIXEIRA, W.C.; SANTOS, H.P.; SILVA, J.C.R.; RIZZO, H.; MARVULO, M.F.V. et al. Perfil zoosanitário dos rebanhos caprinos e ovinos em três mesorregiões do estado do Maranhão, Brasil. Acta Veterinaria Brasilica, v. 9, n. 1, p. 34-42, 2015. Disponível em: https://periodicos.ufersa.edu.br/index.php/acta/article/view/4438 DOI: 10.21708/avb.2015.9.1.4438

VAN WYK, J.A.; STENSON, M.O.; VAN DER MERWE, J.S.; VORSTER, R.J.; VILJOEN, P.G. Anthelmintic resistance in South Africa: surveys indicate an extremely serious situation in sheep and goat farming. Onderstepoort Journal of Veterinary Research, v. 66, n. 4, p. 273-284, 1999. Disponível em: https://www.ncbi.nlm.nih.gov/pubmed/10689700 Acesso em: 22/05/2019.

VIEIRA, M.M.M.; FURTADO, F.M.V.; CÂNDIDO, M.J.D.; BARBOSA FILHO, J.A.D.; CAVALCANTE, A.C.R. et al. Aspectos fisiológicos e bioclimáticos de caprinos nas regiões semiáridas. PUBVET, v. 10, n. 5, p. 356-369, 2016. Disponível em: http://www.pubvet.com.br/uploads/67bf8cdc42674f963c2f38eae0f359cd.pdf Acesso em: 22/05/2019. 